\title{
Human Disease/Clinical Medical Sciences in Dentistry: current state and future directions of undergraduate teaching in the UK and Ireland
}

Atkin $\mathrm{PA}^{1}$, Thomas $\mathrm{S}^{2}$, Cook $\mathrm{RJ}^{3}$, Greenwood $\mathrm{M}^{4}$, Bennett $\mathrm{JH}^{5}$, Willis $\mathrm{A}^{6}$, Donachie $\mathrm{C}^{7}$, Ni Riordain $\mathrm{R}^{8}$, Galvin $S^{9}$, Crighton $A^{10}$, Mighell $A J^{11}$, Bakri $I^{12}$

${ }^{1}$ Cardiff University, ${ }^{2}$ Bristol University, ${ }^{3}$ King's College London, ${ }^{4}$ Newcastle University, ${ }^{5}$ Plymouth University, ${ }^{6}$ Queens University Belfast, ${ }^{7}$ University of Aberdeen, ${ }^{8}$ University College Cork, ${ }^{9}$ University of Dublin, ${ }^{10}$ University of Glasgow, ${ }^{11}$ University of Leeds, ${ }^{12}$ University of Sheffield

\begin{abstract}
In March 2017 a group of teachers of human disease/clinical medical science (HD/CMSD) representing the majority of schools from around the UK and Republic of Ireland met to discuss the current state of teaching of human disease and also to discuss how the delivery of this theme might evolve to inform improved healthcare.
\end{abstract}

This paper outlines how the original teaching in medicine and surgery to dental undergraduate students has developed into the theme of HD/CMSD reflecting changing needs as well as guidance from the regulators, and how different dental schools have developed their approaches to reach their current state.

Each school was also asked to share a strengths, weakness, opportunities and threats (SWOT) analysis of their programme and to outline how they thought their HD/CMSD programme may develop. The school representatives who coordinate the delivery and assessment of HD/CMSD in the undergraduate curriculum have extensive insight in this area and are well-placed to shape the HD/CMSD development for the future. 
This paper is a summary of those discussions and represents the contributions of teachers of human disease from schools in the UK and Ireland.

Corresponding author: Dr Phil Atkin, atkinpa@cardiff.ac.uk 


\section{Human Disease/Clinical Medical Sciences in Dentistry: current state and future directions of undergraduate teaching in the UK and Ireland}

Atkin $\mathrm{PA}^{1}$, Thomas $\mathrm{S}^{2}$, Cook $\mathrm{RJ}^{3}$, Greenwood $\mathrm{M}^{4}$, Bennett $\mathrm{JH}^{5}$, Willis $\mathrm{A}^{6}$, Donachie $\mathrm{C}^{7}$, Ni Riordain $\mathrm{R}^{8}$, Galvin $S^{9}$, Crighton $A^{10}$, Mighell A ${ }^{11}$, Bakri $1^{12}$

${ }^{1}$ Cardiff University, ${ }^{2}$ Bristol University, ${ }^{3}$ King's College London, ${ }^{4}$ Newcastle University, ${ }^{5}$ Plymouth University, ${ }^{6}$ Queens University Belfast, ${ }^{7}$ University of Aberdeen, ${ }^{8}$ University College Cork, ${ }^{9}$ University of Dublin, ${ }^{10}$ University of Glasgow, ${ }^{11}$ University of Leeds, ${ }^{12}$ University of Sheffield

\section{Introduction}

The teaching of Human Disease/Clinical Medical Sciences in Dentistry (HD/CMSD) is an important part of undergraduate dental programmes in order that new graduates are able to practice safely. For example a patient can expect not to come to harm as a consequence of dental treatment because of an avoidable medical complication or drug interaction during a course of treatment. A network of teachers involved in medicine and surgery or human disease teaching for dental students, developed over many years, where topic leads from the different dental schools would meet and compare notes and develop teaching and assessment for their individual schools. A principal recent outcome of this group was agreement in 2011 of a curriculum for clinical medical science in dentistry to act as a framework for topic leads in their respective schools (1). The group continues to meet sporadically, typically when a need arises.

Courses and curricula in HD/CMSD across schools evolved as a result of a number of factors, including ongoing revision of guidance from the GDC and evolving links with medical schools from whom much teaching was obtained. It was felt that a further meeting of the teachers group was needed, to 
evaluate developments in the different schools in the UK and Ireland stood, and what were likely future development intentions.

Invitations were sent to all UK and Ireland dental schools. There then followed a meeting held in Cardiff in March 2017 where participants from many schools around the UK and Ireland met for a one day symposium. Each school representative attending was asked to give a short presentation covering the current state of their HD/CMSD teaching and likely future developments, as well as conduct a Strengths, Weaknesses, Opportunities and Threats (SWOT) analysis. Each delegate was also asked to share as much of their own course material as they felt able as PDFs, presentations or other formats. The collected materials were subsequently distributed amongst those that attended to further aid with the development of HD/CMSD courses in their respective schools. Of the eighteen dental schools delivering undergraduate dental education across the UK and Ireland, twelve were able to attend and contribute. The schools represented were from all the component countries of the United Kingdom as well as both schools in the Republic of Ireland. The schools represented were also a mix of those traditional schools with five year dental programmes, and more recently-established graduate-entry dental schools with a very different history and ethos. The background of the delegates attending was varied also, and included both UK National Health Service (NHS) and university employees, from varied clinical backgrounds including oral medicine, oral and maxillofacial surgery, oral surgery, oral pathology and special care dentistry. Interestingly, the majority of those attending with responsibility for the delivery of HD/CMSD teaching in their schools have degrees in both dentistry and medicine. These persons are well-placed to have good insight into the relevance of, and depth needed for, the medically-related topics contained within the HD/CMSD courses. Some had taken over the role from colleagues in the medical school who formerly ran the 'medicine and surgery' dental undergraduate teaching programmes.

The Development of Medicine \& Surgery, Human Disease/Clinical Medical Science in Dentistry 
Human Disease/Clinical Medical Sciences in Dentistry (HD/CMSD) is a core topic for safe and effective practice in dentistry. The GDC of the UK has issued guidance to dental schools over many years regarding what must be taught in undergraduate dental curricula. From the 1970 's, until its last edition in 1990, the GDC issued successive editions of a document entitled 'Recommendations Concerning the Dental Curriculum' at approximately five year intervals. In 1997, the GDC issued a revised curriculum document, The First Five Years (3), with a second edition in 2002 (4) and an interim third edition in 2008 (5). These were succeeded by further guidance in the documents 'Preparing for Practice' (6) and the 'Preparing for Practice revised edition' (7) in 2015.

Extracts from the 1980 edition of Recommendations Concerning the Dental Curriculum (2) show the guidance that was available to schools to deliver what was then referred to as teaching in Medicine and Surgery. Paragraph 9 stated that 'The dental course falls into three parts. The first part consists of subjects common to medicine and dentistry, extending from anatomy, physiology and biochemistry through pharmacology, pathology and microbiology to medicine and surgery and including many other subjects.' Paragraph 19 required: 'Sufficient instruction in general medicine and surgery and their appropriate specialties should be given to enable the student to understand the manifestations of disease so far as they may be relevant to the practice of dentistry, and it is important that this instruction should involve appropriate teaching on patients attending the medical and surgical departments of a general hospital.' Paragraph 21 recognised the increasing importance of Pharmacology and Therapeutics by stating that: 'The increasing variety and complexity of drugs used in medical and dental treatment, including those used in control of anxiety and pain, add to the importance in the curriculum of pharmacology and therapeutics.' Finally, paragraph 27 deals with assessment requiring that assessment: 'Clinical examinations should be held in medicine and surgery 
It can be taken from this that the GDC were quite aware of the need for dental undergraduate students to be well-versed in medical, surgical and pharmacological knowledge and to be formally examined in these topics.

In the first edition of The First Five Years (3) there was greater clarity regarding instruction in medical and surgical topics, which they grouped collectively as Human Disease. In Paragraph 55 it was noted that 'Part of the undergraduate dental curriculum must be devoted to instruction in medicine and surgery (human disease) and to attendance at accident and emergency departments. A Trust, usually the host Trust, is provided with specific funding to supply the facilities and staff for this part of the curriculum and it must be used for that purpose in agreement with the dental dean or equivalent person.' In Paragraphs 73 to 79 the GDC described in relative detail what it expected dental schools to deliver in HD/CMSD, specifying that this should take place in Medical and Surgical Outpatient clinics and in Accident and Emergency Departments. They emphasised the need for coordinators from the medical school or hospital providing this facility together with a nominated liaison from the dental school. In Paragraph 73 it recognised that 'The course in human disease (medicine and surgery) and in allied subjects, including general pathology and microbiology, has long been held in high regard by those designing dental curricula. When properly delivered, the course provides dental students with a unique insight into the manifestations of human disease and disorders and of the methods employed in treatment. In addition to providing an excellent basis for subsequent studies of clinical dental subjects, the course allows the dentist to communicate effectively thereafter with physicians and surgeons about patients in their joint care.' Later, in Paragraph 74 it commented that 'The courses in general pathology and general microbiology, which may be integrated with one another and with the other subjects in the human disease course, such as immunology, should teach the principles of the subjects concerned using examples from all regions of the body...'

The 1997 edition of the First Five Years went further by offering guidance on delivery. In Paragraph 75 it required that 'Sufficient instruction in human diseases should be given to enable the student to 
understand its manifestations so far as they may be relevant to the practice of dentistry' and that ' Courses require careful structuring and should involve clinical teaching on patients. This may be carried out in in-patient and out-patient medical and surgical department or in specialist clinics situated in teaching or district general hospitals.' Furthermore, they suggested that 'Responsibility for the provision of courses must rest with the heads of university departments of medicine and surgery. Continuity of teaching, preferably by physicians and surgeons who have a particular personal responsibility for teaching dental students is most important. The appointment of a coordinator from within the staff of the dental school is essential.' The GDC also recognised the need for graduating dentists to be fully conversant with drugs used in medicine and dentistry as well as those used in pain and anxiety control. Finally, in this document the GDC recognised the changing pattern of assessment in medicine by allowing an Objective Structured Clinical examination (OSCE) instead of the clinical case-based examination. In August 2002, the GDC published the second edition of The First Five Years (4) and there was some minor refinement of the directions concerning HD/CMSD.

In 2008 a third edition (interim) of The First Five Years was published with a proviso that a further curriculum document would follow in 2010 to replace The First Five Years altogether. This revised document was greatly changed. The new curriculum document used a number of phrases such as 'have knowledge of, 'be familiar with' and 'be competent at' to represent a hierarchy of knowledge in specific areas that a dental student was expected to achieve, and are summarised in table 1. For example, students had to 'Be competent at obtaining a relevant medical history', 'Have knowledge of diagnosing medical emergencies' and 'Be familiar with the general aspects of medicine and surgery' or with the 'main medical disorders that may impinge on dental treatment' or 'the complex interactions between oral health, nutrition, general health, drugs and diseases that can have an impact on dental care and disease'. There was less direct guidance as to how a course should be delivered and by whom, and no mention of by whom and how the teaching in Human Diseases should be managed. Furthermore, there was no mention of how assessments should be conducted. The GDC had shifted its focus towards a loose series of outcomes to be achieved rather than the methods by 
which they should be managed. The direction of how the dental and medical schools should work together, and in particular any mention of specific funding for HD/CMSD had been lost.

In 2011, a fully revised document was published entitled 'Preparing for Practice' (6) and subtitled 'Dental team learning outcomes for registration'. This document had abandoned the hierarchical phrasing 'have knowledge of', 'be familiar with' and 'be competent at' of the earlier curriculum, but it kept the theme of learning outcomes without direction on how they were to be achieved. A second edition of 'Preparing for Practice' was published in 2015 (7), but the statements relating to HD/CMSD remained unchanged from the first edition. These are summarised in Table 2. By 2015 therefore, the latest stage had been reached of continuing evolution of what the GDC requires dental schools to teach undergraduate students in relation to HD/CMSD such that they are safe and competent to begin independent dental practice. The ways by which the dental schools of the UK and Ireland achieve this are different, as described later.

\section{Funding in the UK of Medicine \& Surgery, Human Disease/Clinical Medical Science in Dentistry}

In England and Wales in April 2001 the Multi Professional Education and Training Budget (MPET) was created by the merger of the Non-Medical Education and Training Budget, the Medical and Dental Education Levy, and the Service Increment for Teaching (8). Service Increment for Teaching (SIFT) was established in 1976 following the findings of the Resource Allocation Working Party, a working group within the NHS, and allocated monies to NHS hospitals to account for the additional costs of training medical and dental students within a healthcare service and delivery environment. A separate budget was set aside for dental student teaching within NHS dental hospitals, known as Dental SIFT, and dental hospitals were also allocated a separate Medical for Dental SIFT fund which directly supported the teaching in Medicine and Surgery/Human Disease. This is the funding referred to in paragraph 55 of The First Five Years curriculum document (3). It is this funding which helped to shape the delivery 
of teaching in HD/CMSD which still pertains today in many dental schools, despite the original funding sources being amalgamated into other healthcare funding streams.

\section{Organisation and Delivery of HD/CMSD}

As a result of the original First Five Years (3) document and the funding allocation, many dental schools essentially franchised the teaching and learning in HD/CMSD to their counterpart medical school and retained only a liaising clinician within the dental school structure. Much of the delivery of the teaching of HD/CMSD was provided by clinicians and staff from the medical school and there may have been limited input into the actual content of lectures, practicals and clinical attachments from the dental schools. As had been described above, the sequential curriculum documents from the GDC have evolved such that the instruction for delivery of teaching and assessment of HD/CMSD has changed. Initially it was necessary for dental students to attend accident and emergency departments as well as medical and surgical outpatient clinics and ward rounds. There was a formal assessment in the clinical examination and diagnosis of a real-life medical or surgical patient. Later the clinical exam could be in the form of an objective structured clinical examination (OSCE). In later curriculum documents the GDC was no longer prescriptive of the need for medical and surgical attachments or the mode of examination in HD/CMSD, so long as the stated outcomes were met.

In Cardiff dental school over the last 10 years or so, for example, the teaching and assessment of HD/CMSD has followed the guidance of the relevant GDC documents and at present the teaching still has a large input from the school of medicine. Changes to teaching and assessment practice in the modern environment in both medical and dental schools have resulted in different allocations of staff and resources and the teaching and learning methods of students have also evolved. Following communication with individuals at other dental schools responsible for HD/CMSD it became apparent that there was a need to compare notes across schools to see what approaches to the delivery of HD/CMSD were being used and to share and develop best practice. This resulted in a one day 
symposium held in Cardiff in March 2017, and the following is a summary of the findings of that meeting.

\section{Outcomes of the HD/CMSD Symposium}

Table 3 gives a summary of the teaching and assessment of the HD/CMSD programmes for the participating schools. In relation to in which clinical years the teaching is mostly delivered, there are differences. Some schools primarily deliver the teaching over years 2 and 3 , with others in years 3,4 and 5. An argument for delivering teaching early is that it gives dental students the knowledge, and hopefully the understanding, of human health and disease such that they are safe to begin clinical dental practice on patients, often starting in year 3. A further advantage for some dentistry programmes is that typically in year 1 students will have studied basic sciences such as anatomy, physiology, biochemistry and some basic pharmacology. In year 2 students build on this, looking at pathological mechanisms such as inflammation, immunity, neoplasia and so on, which then translates into year 3 with body-system diseases being taught, for example the respiratory system where inflammation and immunity may be reflected in chronic obstructive pulmonary disease (COPD) and asthma, and neoplasia as lung cancer, for example through smoking. The basic mechanisms of arterial atherosclerosis and cardiac rhythm disorders learned in year 2 translate to the management of hypertension and thrombosis and the use of antihypertensive and anticoagulant medication and how this impacts on dental treatment. The downside of delivering HD/CMSD teaching early is that the students have had limited contact with patients and have taken few medical histories, so the immediate relevance of what they have learned is lost. An advantage of delivering HD/CMSD teaching later in the dental course is that there is immediate relevance to what is being taught and the appreciation and understanding is perhaps greater. 
Where the bulk of the teaching is delivered by colleagues in the medical school there is a tendency to lose sight of the immediate dental relevance of the subjects under discussion, and this is compounded if the teaching is delivered early in the dental course.

Attending delegates were also asked to do a SWOT analysis of their current programmes and share this with the group. Table 4 is a summary of the main themes which came out of this exercise. In the schools where the model of franchised teaching of HD/CMSD was delivered by the medical school, the lecture-based programme was typically delivered by subject experts from medicine and surgery. On the one hand this was seen as a strength, but on the other hand, the lack of dental relevance included in the lectures was a distinct weakness. Often the lectures are a version of, or even the same lectures, that are delivered to medical undergraduates. Despite having specific learning outcomes derived from the various GDC curricula relating to $\mathrm{HD} / \mathrm{CMSD}$, the depth and breadth of the topics may not always be appropriate for dental undergraduate students. Another drawback of having subject experts deliver lectures, is that across the various themes and topics of the HD/CMSD course a large number of individual lecturers may be involved, each with a small part to play and often not well coordinated. The risk is of repetition and overlap in lectures, or worse, missed areas that are not covered within a theme. Without clear reference to the dental relevance of the areas under discussion dental undergraduates were not always able to embrace the teaching, and given that the topics were often taught before many dental students have seen their own patients on clinics and taken many medical histories, the immediate relevance was lost. It is difficult to expect medical specialist lecturers to know the dental relevance of their teaching, but it is this aspect that would help to engage the students in learning and understanding. In addition to this, with contraction of academic university departments in medicine and surgery over recent years, increasing reliance is placed upon colleagues in the NHS or in clinical service provision to deliver teaching. This may be done on a grace and favour basis or on personal relationships with individual clinicians and may not be reflected in job-planning of nonuniversity staff. Furthermore, the demands of service provision may override those of teaching which may result in short-notice cancellation of teaching and rescheduling of lectures out of sequence, which 
again disheartens dental students and leads to dissatisfaction with the course and poor feedback. A further aspect of the dental school links to the hospital is the change in structure in medicine and surgery care. There has been a shift from a 'clinical firm' (e.g. house officers, senior house officers and a registrar) with a lead consultant, which would admit and look after patients under the care of a named consultant. This has been replaced by a shift-based system where junior doctors looked after all medical or surgical patients no matter who is their named consultant. The former stable hierarchical structure of a 'firm' has now a constantly shifting group of junior staff. Trying to match this new arrangement to a group of observing dental students on a clinical attachment often proves impossible, where there is no consistent supervising consultant to give a lead to teaching and learning Another aspect of franchising HD/CMSD teaching to the medical school is that where there is a single individual in the dental hospital responsible for coordinating the teaching (and assessment), the loss of that individual through retirement or change in role leaves a large gap. The 'institutional memory' or 'institutional knowledge' invested in that individual is lost and the relationships developed with the medical school and hospital clinicians is also lost (9). To quote from one such paper warning of "...the loss of institutional knowledge from those retiring, and the impacts these could have ..." is immediately applicable to many HD/CMSD programmes (10).

In the discussion of opportunities, a few themes emerged which relate to bringing HD/CMSD teaching in-house. The first is that if the teaching is delivered by dentally-qualified staff, then the lack of dental relevance described above when subject experts deliver lectures is overcome, and examples of real dental patient care can be used to illustrate teaching. Additionally, the depth and breadth of teaching can be better matched to dental student learning needs. The reclaim of any budget used for HD/CMSD teaching (medical for dental SIFT as was) may also allow for investment in dental staff to help to deliver small-group teaching with better opportunities for discussion, case-based learning and personalised student feedback. The staffing demands for small group teaching are large however. 
Finally two further themes mentioned were the possibility for integrating HD/CMSD teaching with similar areas such as Special Care Dentistry where the dentistry may be relatively straightforward but the wider medical needs of the patient are great. Secondly the use of blended learning where online resources can serve to replace some of the lectures formerly used, which may include the use of lecture capture software, allowing students to access recorded lectures at a time of their own convenience.

In the discussion on threats to HD/CMSD teaching and learning, the increasing lack of detail supplied by the GDC in the various iterations of curriculum documents was highlighted. Whereas formerly the documents were very specific about how, where and by whom HD/CMSD topics would be taught (and funded), the later documents were increasingly vague. Many schools continue with versions of the model of lectures given by subject specialists from the medical school, there is a gradual trend to move away from this to small group teaching by dental staff. In the newer dental schools where there is no such tradition, and even no close physical link to a nearby medical school or hospital, the teaching of $\mathrm{HD} / \mathrm{CMSD}$ may be delivered continuously through a vertically-integrated programme or in what has been described as 'spiral learning' throughout the BDS course. Also, these schools may not always have clinical teaching staff in oral medicine or OMFS or other relevant disciplines who could be called upon to shape and/or deliver such teaching from a background of medicine and dentistry to inform the depth and breadth of teaching.

\section{Conclusion}

The teaching of HD/CMSD in the UK and Ireland appears to be in a state of flux with some schools employing a system of close collaboration with an allied medical school or hospital and the use of lectures and clinical attachments to meet the learning outcomes of the GDC or the Dental Council of 
Ireland. In other schools there is no well-defined block of teaching that could be described as solely $\mathrm{HD} / \mathrm{CMSD}$ and the teaching in this area occurs longitudinally though the BDS course and is assessed at different times and in different ways. Lying somewhere between these two models are schools who have brought HD/CMSD teaching in-house (as well as the budget) and are developing small-group teaching models, complemented by lectures from dental school staff from different dental specialties and supported by online learning packages which students can access at their own convenience and discuss in tutorials, seminars or other small-group sessions. It should be noted that the consensus of the teachers of HD/CMSD was that online resources were helpful to, but could not replace, face-toface teaching and learning where real-life examples of patients and situations could be drawn upon by experienced clinicians to illustrate or explain a more complex concept or problem.

The importance of HD/CMSD teaching in the undergraduate curriculum has never been greater. The population in the UK (and elsewhere) is getting older, with $18 \%$ aged 65 and over and $2.4 \%$ aged 85 and over (11), and with age comes many medical comorbidities and necessary associated polypharmacy (12). There are also those patients in the population with special needs (13) who put a greater demand on the skills, knowledge and experience of dental practitioners in the community and in hospital dentistry. The need for a solid foundation in clinical medical science from undergraduate studies and continuing medical education is established and ever increasing. 
References

(1) Mighell AJ, Atkin PA, Webster K et al. Clinical medical sciences for undergraduate dental students in the United Kingdom and Ireland - a curriculum. European Journal of Dental Education. 2011:15(3):179-88

(2) Recommendations Concerning the Dental Curriculum. General Dental Council, London 1980

(3) The First Five Years. General Dental Council, London 1997

(4) The First Five Years $2^{\text {nd }}$ Edition. General Dental Council, London 2002

(5) The First Five Years $3^{\text {rd }}$ Edition (Interim) General Dental Council, London 2008

(6) Preparing for Practice. General Dental Council, London 2011

(7) Preparing for Practice $2^{\text {nd }}$ Edition (Revised) General Dental Council, London 2015

(8) Funding learning and development for the healthcare workforce. Department of Health, London 2002

(9) Carey WD. On institutional memory. Science. 1986 Oct 3;234(4772):9.

(10) Retaining institutional wisdom: using an evidence-informed approach to transfer knowledge from experienced nurses to new nursing staff. Canadian Health Services Research Foundation. Health Policy. 2009 May;4(4):57-60.

(11) Overview of the UK population: July 2017 Office for National Statistics. https://www.ons.gov.uk/releases/overviewoftheukpopulationjuly2017 Accessed 31.7.17

(12) NobiliS, Garattini S, Mannucci PM. Multiple diseases and polypharmacy in the elderly: challenges for the internist of the third millennium. Journal of Comorbidity 2011;1:28-44

(13) Glassman P, Subar P. Improving and Maintaining Oral Health for People with Special Needs Dent Clin N Am 2008 52:447-461 
Table 1

The hierarchy of knowledge from the GDC documents The First Five Years, $3^{\text {rd }}$ Edition. (5)

\begin{tabular}{|l|l|}
\hline Statement & Descriptor \\
\hline Be familiar with: & $\begin{array}{l}\text { Students should have a basic understanding of the subject, but need not have direct clinical } \\
\text { experience or be expected to carry out procedures independently. }\end{array}$ \\
\hline Have knowledge of: & $\begin{array}{l}\text { Students should have a sound theoretical knowledge of the subject, but need have only a limited } \\
\text { clinical/practical experience. }\end{array}$ \\
\hline Be competent at: & $\begin{array}{l}\text { Students should have a sound theoretical knowledge and understanding of the subject together } \\
\text { with an adequate clinical experience to be able to resolve clinical problems encountered, } \\
\text { independently, or without assistance. }\end{array}$ \\
\hline
\end{tabular}


Table 2

The HD/CMSD Learning Outcomes from Preparing for Practice $2^{\text {nd }}$ Edition (7)

\begin{tabular}{|c|c|c|}
\hline \multirow{2}{*}{$\begin{array}{l}\text { Clinical } \\
\text { Paragraph }\end{array}$} & \multicolumn{2}{|c|}{$\begin{array}{l}\text { Upon registration with the GDC the registrant will be able to demonstrate the outcomes as relevant to the practice of dentistry and } \\
\text { patient care }\end{array}$} \\
\hline & Item & Outcome \\
\hline 1. & Individual patient care & \\
\hline \multirow[t]{4}{*}{1.1} & Foundations of practice & $\begin{array}{l}\text { 1.1.4 Identify general and systemic disease and explain their relevance to oral health and their impact on } \\
\text { clinical treatment }\end{array}$ \\
\hline & & $\begin{array}{l}\text { 1.1.8 Explain the potential routes of transmission of infectious agents in dental practice, mechanisms for the } \\
\text { prevention of infection, the scientific principles of decontamination and disinfection and their relevance to } \\
\text { health and safety }\end{array}$ \\
\hline & & $\begin{array}{l}\text { 1.1.9 Describe the properties of relevant drugs and therapeutic agents and discuss their application to patient } \\
\text { management }\end{array}$ \\
\hline & & $\begin{array}{l}\text { 1.1.13 Explain, evaluate, and apply to clinical practice psychological and sociological concepts and theoretical } \\
\text { frameworks of health, illness, behavioural change and disease }\end{array}$ \\
\hline \multirow[t]{4}{*}{1.2} & $\begin{array}{l}\text { Comprehensive patient } \\
\text { assessment }\end{array}$ & 1.2.1 Obtain, record, and interpret a comprehensive and contemporaneous patient history \\
\hline & & 1.2.2 Undertake an appropriate systematic intra- and extra-oral clinical examination \\
\hline & & 1.2.3 Manage appropriate clinical and laboratory investigations \\
\hline & & 1.2.4 Undertake relevant special investigations and diagnostic procedures, including radiography \\
\hline 1.5 & Treatment planning & $\begin{array}{l}\text { 1.5.2 Describe the range of orthodox complementary and alternative therapies that may impact on patient } \\
\text { management }\end{array}$ \\
\hline \multirow[t]{3}{*}{1.7} & Patient management & 1.7.2 Identify, explain and manage the impact of medical and psychological conditions in the patient \\
\hline & & 1.7.8 Safely and appropriately prescribe and administer drugs and therapeutic agents \\
\hline & & 1.7.9 Explain the role and organisation of referral networks, clinical guidelines and policies and local variation \\
\hline
\end{tabular}




\begin{tabular}{|l|l|l|}
\hline \multicolumn{2}{|l|}{} & \\
\hline \multicolumn{2}{|l|}{} & $\begin{array}{l}1.7 .10 \text { Explain the need to take responsibility for establishing personal networks with local dental and medical } \\
\text { colleagues, specialists and other relevant individuals and organisations }\end{array}$ \\
\hline 1.8 & Patient and public safety & $\begin{array}{l}1.8 .2 \text { Implement, perform and manage effective decontamination and infection control procedures according } \\
\text { to current guidelines }\end{array}$ \\
\hline \multirow{2}{*}{$\begin{array}{l}\text { Health promotion and } \\
\text { disease prevention }\end{array}$} & 1.10 .1 Recognise the responsibilities of a dentist as an access point to and from wider healthcare \\
\hline \multirow{2}{*}{} & $\begin{array}{l}1.10 .4 \text { Underpin all patient care with a preventive approach that contributes to the patient's long-term oral } \\
\text { and general health }\end{array}$ \\
\cline { 2 - 3 } & $\begin{array}{l}1.10 .7 \text { Evaluate the health risks of diet, drugs and substance misuse, and substances such as tobacco and } \\
\text { alcohol on oral and general health and provide appropriate advice and support }\end{array}$ \\
\hline
\end{tabular}


Table 3

A summary of teaching and assessment in the participating schools

\begin{tabular}{|c|c|c|c|c|c|c|c|c|}
\hline Dental School & $\begin{array}{l}\text { Which years in the } \\
\text { BDS course } \\
\text { HD/CMSD teaching } \\
\text { is delivered }\end{array}$ & $\begin{array}{c}\text { Which year(s) in } \\
\text { the BDS course is } \\
\text { HD/CMSD } \\
\text { formally assessed }\end{array}$ & $\begin{array}{c}\text { Teaching } \\
\text { predominantly } \\
\text { by medical } \\
\text { staff }\end{array}$ & \begin{tabular}{|c|} 
Teaching \\
predominantly \\
by dental staff
\end{tabular} & $\begin{array}{l}\text { In-house online } \\
\text { teaching/resource }\end{array}$ & \begin{tabular}{|c|} 
PBL/small \\
group \\
teaching \\
incorporated \\
\end{tabular} & $\begin{array}{c}\text { Clinical } \\
\text { attachments }\end{array}$ & $\begin{array}{l}\text { Clinical } \\
\text { or } \\
\text { OSCE } \\
\text { exam } \\
\end{array}$ \\
\hline Aberdeen & $2,3,4,5$ & $2,3,4,5$ & even & even & $\mathrm{N}$ & $\mathrm{Y}$ & $\mathrm{Y}$ & $\mathrm{Y}$ \\
\hline Belfast & 3 & 3 & $x$ & & $\mathrm{~N}$ & $\mathrm{~N}$ & $\mathrm{Y}$ & $\mathrm{Y}$ \\
\hline Bristol & $1,2,3$ & 3 & $x$ & & $\mathrm{~N}$ & $\mathrm{Y}$ & $\mathrm{Y}$ & $\mathrm{Y}$ \\
\hline Cardiff & 2,3 & 3 & $x$ & & $\mathrm{~N}$ & $\mathrm{~N}$ & $\mathrm{~N}$ & $\mathrm{~N}$ \\
\hline Cork & 3,4 & 4 & $x$ & & $\mathrm{~N}$ & $\mathrm{Y}$ & $Y$ & $\mathrm{~N}$ \\
\hline Dublin & 3 & 3 & $x$ & & $\mathrm{Y}$ & $Y$ & $Y$ & $Y$ \\
\hline Glasgow & $2,3,4,5$ & $2,3,4,5$ & & $x$ & $\mathrm{~N}$ & $\mathrm{Y}$ & $\mathrm{N}$ & $\mathrm{Y}$ \\
\hline Kings London & 2,3 & 3,5 & & $x$ & $\mathrm{Y}$ & $\mathrm{Y}$ & $\mathrm{N}$ & $Y$ \\
\hline Leeds & 4,5 & 4,5 & & $x$ & $Y$ & $\mathrm{Y}$ & $Y$ & $Y$ \\
\hline Newcastle & 3,4 & 3,4 & $x$ & & $Y$ & $\mathrm{Y}$ & $\mathrm{N}$ & $Y$ \\
\hline Peninsula & $2,3,4$ & $1,2,3,4,5$ & $x$ & & $Y$ & $Y$ & $\mathrm{~N}$ & $\mathrm{~N}$ \\
\hline Sheffield & 2,3 & 3 & $x$ & & $\mathrm{~N}$ & $\mathrm{Y}$ & $\mathrm{Y}$ & $\mathrm{Y}$ \\
\hline
\end{tabular}


Table 4

Summary of the SWOT analysis themes in the participating schools

\begin{tabular}{|c|c|c|c|}
\hline Strengths & Weaknesses & Opportunities & Threats \\
\hline $\begin{array}{l}\text { Teaching from } \\
\text { (medical/surgical) subject } \\
\text { experts can be good } \\
\text { Where the dental school } \\
\text { has control over budget, } \\
\text { teaching can be more } \\
\text { dentally-focussed } \\
\text { In-house HD/CMSD } \\
\text { teaching allows for } \\
\text { integration throughout the } \\
\text { BDS course } \\
\text { Increased dental relevance } \\
\text { means better student } \\
\text { engagement and feedback }\end{array}$ & $\begin{array}{l}\text { Lack of dental context and relevance } \\
\text { from non-dental lecturers } \\
\text { Lack of control of HD/CMSD budget } \\
\text { makes increasing the staff/time for } \\
\text { teaching very difficult } \\
\text { Teaching of HD/CMSD early in the } \\
\text { BDS course means students can't see } \\
\text { immediate relevance and importance } \\
\text { - leads to loss of engagement } \\
\text { Where there is a single staff member } \\
\text { in the dental school responsible for } \\
\text { HD/CMSD teaching and assessment, } \\
\text { succession planning and support is } \\
\text { essential } \\
\text { Using clinical medical staff in } \\
\text { teaching risks late-notice changes } \\
\text { where clinical commitments override } \\
\text { teaching responsibilities }\end{array}$ & $\begin{array}{l}\text { Bringing HD/CMSD in-house from } \\
\text { medical school can increase control } \\
\text { and opportunity to develop dental } \\
\text { relevance of course } \\
\text { Bringing control/budget for } \\
\text { HD/CMSD in-house may allow for } \\
\text { increased small group teaching and } \\
\text { better explanation of dental } \\
\text { relevance } \\
\text { Moving HD/CMSD teaching to later in } \\
\text { the BDS course may improve } \\
\text { understanding and engagement } \\
\text { Engaging with Special Care Dentistry } \\
\text { and similar may spread the load of } \\
\text { teaching and increase student } \\
\text { engagement } \\
\text { To develop blended and/or online } \\
\text { learning to improve student access to } \\
\text { teaching resource (to support small } \\
\text { group teaching) }\end{array}$ & $\begin{array}{l}\text { Reduction of HD/CMSD detail in } \\
\text { sequential GDC curricula may allow } \\
\text { dental schools to reduce HD/CMSD } \\
\text { teaching to the detriment of students } \\
\text { and patients } \\
\text { Loss of detail/focus by GDC curricula } \\
\text { in HD/CMSD may lead to school } \\
\text { reducing commitment and budget } \\
\text { allocation } \\
\text { Reduced focus on whole patient care } \\
\text { and increasing focus on technical } \\
\text { aspects of dentistry } \\
\text { Job-planning of HD/CMSD course } \\
\text { leaders to reduce teaching time and } \\
\text { increase direct clinical care } \\
\text { (especially in non-university staff) } \\
\text { Geographical relocation of dental } \\
\text { schools away from medical } \\
\text { schools/hospitals may reduce links to } \\
\text { medical specialties }\end{array}$ \\
\hline
\end{tabular}


END 